Canadian Journal of Fisheries and Aquatic Sciences

Canadian Science Publishing Journal canadien des sciences halieutiques et aquatiques

\title{
Phenotypic integration of behavioural and physiological traits is related to variation in growth among stocks of Chinook salmon
}

\begin{tabular}{|r|l|}
\hline Journal: & Canadian Journal of Fisheries and Aquatic Sciences \\
\hline Manuscript ID & cjfas-2017-0367.R1 \\
\hline Manuscript Type: & Article \\
\hline Date Submitted by the Author: & 31 -Jan-2018 \\
\hline Complete List of Authors: & $\begin{array}{l}\text { Dender, Mitchel; University of Windsor, GLIER } \\
\text { Capelle, Pauline ; University of Windsor, GLIER } \\
\text { Love, Oliver; University of Windsor, GLIER } \\
\text { Heath, Daniel; University of Windsor } \\
\text { Heath, John; Yellow Island Aquaculture Ltd., } \\
\text { Semeniuk, Christina; University of Windsor, GLIER }\end{array}$ \\
\hline $\begin{array}{r}\text { Is the invited manuscript for } \\
\text { consideration in a Special } \\
\text { Issue? : }\end{array}$ & N/A \\
\hline Keyword: & $\begin{array}{l}\text { AQUACULTURE < General, Behaviour, Diel cortisol, GROWTH < General, } \\
\text { Chinook salmon }\end{array}$ \\
\hline \multicolumn{2}{|c}{} \\
\hline
\end{tabular}


1 Phenotypic integration of behavioural and physiological traits is related to

2 variation in growth among stocks of Chinook salmon

4 MITCHEL G.E. DENDER ${ }^{1}$, PAULINE M. CAPELLE ${ }^{2}$, OLIVER P. LOVE ${ }^{2}$, DANIEL D.

5 HEATH ${ }^{1}$, JOHN. W. HEATH ${ }^{3}$, CHRISTINA A.D. SEMENIUK ${ }^{1, *}$

$7 \quad{ }^{1}$ Great Lakes Institute for Environmental Research, University of Windsor, Windsor, Ontario

$8 \quad$ N9B 3P4, Canada

$9{ }^{2}$ Department of Biological Sciences, University of Windsor, Windsor, Ontario N9B 3P4, Canada

$10{ }^{3}$ Yellow Island Aquaculture Ltd., Heriot Bay, BC, Canada VOP $1 H 0$

$12 *$ Corresponding author. Great Lakes Institute for Environmental Research, University of

13 Windsor, 401 Sunset Ave., Windsor, Ontario, Canada N9B 3P4. Tel.: +1 5192533000 ext. 3763

15 E-mail address: semeniuk@uwindsor.ca (C.A.D. Semeniuk)

17 Running headline: Phenotypic integration benefits salmon growth 


\section{Abstract}

19 The selection for a single organismal trait like growth in breeding programs of farmed

20 aquaculture species can counter-intuitively lead to lowered harvestable biomass. We outbred a

21 domesticated aquaculture stock of Chinook salmon (Oncorhynchus tshawytscha) with 7 wild

22 stocks from British Columbia, Canada. We then examined how functionally related traits

23 underlying energy management - diel variation in cortisol; foraging, social, and movement

24 behaviours - predicted stock-level variation in growth during the freshwater life history stage, a

25 performance metric under aquaculture selection. Outbreeding generated significant variation in

26 diel cortisol secretion and behaviours across stocks, and these traits covaried, suggesting tight

27 integration despite hybridization. The coupling of nighttime cortisol exposure with daytime

28 behavioural phenotype was the strongest predictor of stock-level variation in body mass. Our

29 results suggest selecting for an integrated phenotype rather than on single mechanistic traits

30 alone can generate the greatest effect on aquaculture fish growth under outbreeding practices.

31 Furthermore, selecting for these traits at the stock level may increase efficiency of farming

32 methods designed to consistently maximize fish performance on a large scale.

34 Key words: Aquaculture, Behaviour, Diel cortisol, Phenotypic integration, Functional traits, 35 Growth, Chinook salmon, 


\section{Introduction}

For the first time on record, people are consuming more farm-raised than wild-caught fish

38 (FAO 2016), and urbanization is simultaneously creating a greater demand for both improved

39 quantity and quality protein due to its recognition in healthy diets (Clapp \& Cohen 2009;

40 Henchion et al. 2017). Aquaculture production has been relieving the pressure on wild fish

41 populations by attempting to provide a more sustainable and economic source of protein (FAO

42 2016). However, aquaculture faces the same challenges as other farming practices: to harvest the

43 greatest amount of product at the minimum operator cost. As with any domestication process,

44 fish stocks have the tendency to inadvertently become inbred when only selecting the largest,

45 fastest growing individuals as broodstock (Bentsen \& Olesen 2002), thereby becoming

46 susceptible to disease (Arkush et al. 2002), experiencing slower growth (Kincaid 1983), or

47 having low fecundity (Su et al. 1996). (Re)introducing alleles at fertilization is the classic

48 method of lessening the effects of inbreeding depression via the outbreeding of domestic

49 broodstock with wild individuals (Lehnert et al. 2014). First generation (F1) hybrid offspring of

50 wild-caught and domesticated parents may experience benefits associated with outbreeding such

51 as increased size (i.e., hybrid vigour: Gharrett et al. 1999; Whitlock et al. 2000). However, stocks

52 may also experience outbreeding depression (Allendorf et al. 2001; Neff et al. 2011), whereby a

53 shift in mean phenotype occurs and causes a reduction in growth (Tymchuk et al. 2006) and

54 survival (Gharrett et al. 1999; Tallmon et al. 2004; Edmands 2007). These discrepancies can be

55 explained through the evolutionary concept of an integrated phenotype (Murren 2012), which

56 recognizes that optimal functioning of the organism requires multiple traits to work in unison. As

57 such, when genetic recombination disrupts the evolutionary orchestration of integrated traits,

58 individual performance and fitness can be compromised (Lancaster et al. 2010). 
To enhance the performance of captive stocks, aquaculture producers should ideally be

60 able to assess whether the genotypes selected for outcrossing will maintain the expression of

61 maximal performance metrics such as growth through the continued integration of key

62 phenotypic traits (e.g., traits related to energetic management) that ultimately increase harvest

63 biomass (Tallmon et al. 2004). One of these metrics is the ability to manage energetic

64 homeostasis, both physiologically and behaviourally, since energetic management is widely

65 recognized as critical for maximizing growth in aquaculture (Boisclair and Sirois 1993;

66 Silverstein et al. 1999). In particular, diel management of baseline levels of glucocorticoids is

67 important for overall energetic balance via the optimal timing of fuel mobilization (e.g., glucose,

68 lipids, and fatty acids; Gregory and Wood 1999). Likewise, behavioural traits related to

69 energetics such as aggression, schooling, neophilia, and coping style all directly affect the ability

70 of an individual to acquire, consume, and efficiently convert food to tissue (Gregory and Wood

71 1999; Almazán-Rueda et al. 2005; Martins et al. 2006). Collectively, physiological and

72 behavioural traits related to energy management are expected to impact fitness (Gilmour et al.

73 2005), yet the linkages among these traits in novel environments remain largely unexplored.

Here we apply the framework of phenotypic integration (Ketterson et al. 2009; Lancaster

75 et al. 2010; Murren 2012) to assess the impacts of outbreeding on performance at an important

76 early life-history stage within an emerging model of Pacific salmonid aquaculture (Chinook

77 salmon; Oncorhynchus tshawytscha). Specifically, our objectives are to determine whether: 1)

78 outcrossing a domesticated stock with multiple wild populations generates variability in traits

79 expected to impact juvenile growth (e.g., diel cortisol patterns, exposure to cortisol during

80 nighttime and daytime, and behavioural phenotype); 2) physiological and behavioural traits are

81 tightly coupled; and 3) taking an integrative, compared to a traditional, single-trait approach, 
82 better predicts variation in growth in an aquaculture setting. We examine these questions using a

83 domesticated stock outbred with wild genotypes from 7 regional populations in coastal British

84 Columbia, Canada. We focused these questions on an early-life stage given the recently

85 highlighted importance of identifying mechanisms controlling early development since these are 86 considered significant for the determination of developmental windows that most impact growth

87 variation and survival (Valente et al. 2013). Given the high degree of local adaptation of

88 semelparous Pacific salmon (Taylor 1991), reflecting the environment-specific functional

89 properties of specific loci (Carlson \& Seamons 2008), our chosen system also provides the

90 unique opportunity to examine whether physiology and behaviours associated with energy

91 management become decoupled in a hybrid F1 generation, and whether the expression of energy-

92 management phenotypes is optimally related to growth in a novel, captive environment. Given

93 that adaptive covariation between physiology and behaviour should be ultimately linked to

94 performance (McGlothlin et al. 2007), selection for suitable captive phenotypes expressing

95 optimal cortisol-behavioural trait combinations should be critical for producing the ideal farmed

96 fish. As such, we expected hybridized stocks expressing an optimal combination of low daytime

97 baseline cortisol (representing low energetic demand), intermediate nighttime baseline cortisol

98 (representing the ability to mobilize energy without entering stress-induced levels; Mommsen et

99 al. 1999), and favorable energy management behaviours (e.g., high foraging rates, high sociality, 100 and lower movement) to exhibit the largest mean body mass. 
Methods

106 Animal husbandry and growth

107 Research was conducted at Yellow Island Aquaculture Ltd. (YIAL) on Quadra Island, British

108 Columbia (latitude: N 50 7' 59.124"; longitude: W 125 19' 51.834"). The YIAL Chinook

109 salmon population originated from crosses made in 1985 from two nearby hatcheries: Robertson

110 Creek (latitude: N 49 18' 37.8792"; longitude: W 124 57' 36.4392") and Big Qualicum River

111 (latitude: $\mathrm{N} 49^{\circ} 21^{\prime}$ 56.3616"; longitude: W 124 39' 6.2964"). The domesticated YIAL stock has

112 been maintained in captivity for seven generations. In 2013, sires from 7 wild stocks originating

113 from tributaries on Vancouver Island and the lower mainland of British Columbia (Figure 1)

114 were selected for generating outbred crossed stocks with YIAL dams, with an additional YIAL $\mathrm{x}$

115 YIAL stock serving as a control (Semeniuk et al. submitted). Gamete collection and fertilization

116 occurred during October and November of 2013, with milt of 10 males from each stock

117 fertilizing mixed eggs from 17 YIAL dams, who were the offspring of self-fertilization in one

118 functional hermaphrodite, to control for known maternal effects on growth (Heath et al. 1999).

119 After incubation in vertical-stack trays, fry were transferred on March 14, 2014 to $200 \mathrm{~L}$ barrels

120 (mean: $122 \pm 5$ fish per barrel; range: 120-136) split by stock and duplicated to account for barrel

121 effects ( $\mathrm{n}=16$ barrels), with a flow through water system maintained between $10-12{ }^{\circ} \mathrm{C}$ and water

122 turnover at $1 \mathrm{~L} / \mathrm{min}$. All barrels were cleaned approximately every 7 days and dissolved oxygen

123 was monitored once a week and maintained above $80 \%$ saturation. Fish were fed to satiation 8

124 times daily between 8:00am to 5:00pm, and mortalities removed every two days (mean mortality 125 rate (March 26-June 4, 2014): $2.52 \pm 3.9 \%$ per barrel; range: 0-16 fish). For this study, barrels for 126 each stock consisted of a mixture of all 10 families. On June 6, 2014, a random subset of 10-13

127 individual fish were removed from every barrel, individually weighed to the nearest $0.01 \mathrm{~g}$, and 
128 fish were returned to their original barrel. Body mass at this stage was used as our performance

129 metric to represent early growth from the fry stage, a critical freshwater life-history stage under 130 strong selection in aquaculture (Piper et al. 1982).

\section{Blood sampling and cortisol assays}

133 We sampled fish for diel cortisol patterns at 8 months post fertilization, over a three-day period

134 beginning on June 25, 2014. Specifically, six fish from each stock were sampled (alternating 135 between barrel replicates) at 6 time periods across the entire diel cycle for a total sample size of 13636 fish per stock (Figure 2A). These specific sampling times were chosen to represent both key

137 periods over the 24-hour period where fish have been shown to be active behaviourally and

138 physiologically (Thorpe et al. 1987; Gries et al. 1997; Pavlidis et al. 1999; Bremset 2000), to 139 capture as much finer-scale variation with day- and night-time periods as possible. Fish were 140 captured via dip net, immediately euthanized in a clove oil solution, and blood was collected via 141 caudal severance using heparinized hematocrit tubes. All sampling was completed within 5

142 minutes of the initial disturbance to account for increases in cortisol due to capture and handling, 143 and a given barrel was only sampled once every 24 hours to ensure that individuals had not been 144 disturbed from a previous capture session. Packed red blood cells were then separated from 145 plasma via centrifugation at $14,000 \mathrm{rpm}(13,331 \mathrm{~g})$ and plasma was stored at $-80^{\circ} \mathrm{C}$ until further 146 analyses. Baseline plasma cortisol was determined using a cortisol enzyme-linked 147 immunosorbent assay (Cayman Chemical, MI, USA) optimized in-house for use in juvenile 148 Chinook salmon (Capelle et al. 2016). Samples were run in triplicate across fourteen assay plates 149 at 1:20 dilution. Individual assay plates included standard curves and common control samples, 
150 and were read at a wavelength of $412 \mathrm{nM}$ using a spectrophotometer (Biotek Inc). Inter- and 151 intra-assay coefficients of variation were $11.0 \%$ and $4.6 \%$, respectively.

\section{Behavioural analysis}

154 All barrels (2 barrels per stock) were each filmed once over a span of seven days (June 3-10, 155 2014). GoPro cameras (Woodman Labs, USA) were placed on the bottom center of the barrels at $156 \sim 6: 00$ am and behaviours were recorded for 1.5 hours. At 1 hour post camera deployment, fish in 157 the barrels were fed $\sim 4.2 \mathrm{~g}$ of feed. Feed amount was calculated using Taplow Feeding charts 158 (Chilliwack, BC, Canada), with daily amounts representing $\sim 2 \%$ of the biomass in a barrel to 159 match a satiated growth promotion diet. Behavioural analyses consisted of: assigning a score to 160 the degree of group cohesion, calculating individual swimming velocity, and scoring uniformity 161 of gregarious swimming direction fifteen minutes prior and post the addition of food, at one162 minute intervals. During food presentation, position and movement of a subset of fish $(\sim 60)$ were

163 noted, as well as latency (in seconds) to resume pre-feeding behaviours (see supplementary 164 materials, Tables S1 and S2). Behavioural videos of the Capilano-River stock were highly 165 distorted due to unforeseen technical issues and thus this population was excluded from all 166 behavioural analysis.

\section{Statistical analysis}

169 All analyses were conducted using JMP version 12 (SAS Institute Inc.), except where indicated.

170 Prior to analysis, model assumptions of normality and homogeneity of variances were tested by 171 visual inspection of residual versus predicted plots, and normality was confirmed using the 
172 Shapiro-Wilk test. Non-normally distributed data were $\log ^{10}$ transformed where indicated. In all 173 cases, results were evaluated for significance at $\alpha=0.05$.

174 To describe diel cortisol variation across all stocks, a general linear model with stock,

175 time of day, and their interaction included as fixed effects was used. Cortisol data were $\log ^{10}$

176 transformed to achieve normality. Next, the area under the diel cortisol curve (AUC) was

177 calculated for daytime (6am-6pm) and nighttime (6pm-6am) cortisol (see Figure 2A), following

178 Pruessner et al. (2003) as an estimate of the amount of hormone fish were exposed to

179 (aggregated at the stock level), and as a means to capture the potential different roles of cortisol

180 across the 24-hour cycle. Daytime and nighttime cortisol exposures were pooled separately for

181 each stock but differences were examined using a paired t-test.

183 Behavioural variables from video recordings were grouped a priori into three categories with

184 known implications for fish growth and consisting of distinct variables: Foraging, Sociality, and

185 Movement (Fernö et al., 1988; Fernö et al., 1995; Oppedal et al., 2011). A principal component

186 analysis (PCA) with varimax rotation was used for initial exploration of each behavioural

187 category independently to reduce redundancies in the data and to create more homogenous

188 groupings. Each 'factor' extracted explained a minimum of $35 \%$ of the variance in behaviour

189 based on the Kaiser criterion (eigenvalue $>1$ ) and visual inspection of variance plots (Table S1),

190 and were retained for the second stage of PCA. In the second stage, the rotated factors resulting

191 from each behavioural category were loaded into a PCA to produce an overall behavioural

192 phenotype. This PCA produced only a single component with an eigenvalue score that was $>1$

193 (eignevalue $=2.3$ ), explained $38.3 \%$ of the overall variance, and was used in subsequent models.

194 High positive scores were associated with fish that spent longer time feeding, retained group 
195 cohesiveness, and collectively exhibited consistent swimming directions, suggestive of more

196 efficient energetic management.

197 To investigate the effects of cortisol and behaviour on growth, analyses were conducted

198 using daytime and nighttime cortisol exposure separately. To first confirm the coupling of

199 cortisol during daytime and nighttime directly with behaviour, we used a linear regression with

200 the behavioural phenotype score regressed against cortisol exposure $\left(\mathrm{AUC}_{\text {night }}\right.$ or $\mathrm{AUC}$ day $)$.

201 Next, we assessed whether each trait in isolation or in combination influenced size using linear

202 regressions with mean body mass per population as the response variable (from the sub-sample

203 of individuals weighed prior to the experiment and averaged across replicate barrels), and

204 population-level behavioural phenotype with nighttime cortisol exposure $\left(\mathrm{AUC}_{\text {night }}\right)$ or daytime

205 cortisol exposure $\left(\mathrm{AUC}_{\text {day }}\right)$ as the explanatory variables. Both linear and quadratic terms for

206 cortisol and behaviour were used in a subset of models to account for any hormetic relationships

207 (Schreck 2010). For model selection, we used a combination of fit, significance, and AIC

208 modified for small sample size (AICc) using the package "AICcmodavg” in R (Mazerolle and

209 Mazerolle 2017).

210

211 All analyses were aggregated to the level of the population since screening at the individual level

212 is not necessarily a feasible practice within aquaculture (Castanheira et al. 2013; Pigliucci, 2003).

213 Instead, determining whether integrated phenotypes exist at the population level is not only

214 practical, but since intraspecific variability influences fundamental evolutionary processes of

215 adaptation (Bennett et al. 2016), it also increases the potential that the desired phenotypes will

216 remain robust under the stresses of captivity in subsequent generations. 


\section{Results}

219 Variation in diel cortisol and behaviour among stocks

220 Stock and time of day interacted to influence baseline cortisol levels $\left(F_{47,279}=14.01, n=280, p<\right.$ 221 0.001). While each stock showed similar diel rhythms in their baseline cortisol (Figure 2A), they 222 differed in overall exposure to cortisol across the full 24-hour cycle (Figure 2B). In addition, 223 daytime cortisol exposure was significantly lower than nighttime exposure (paired t(6) $=5.59, p$ $224<0.001)$. The behavioural phenotype scores for different stocks ranged from -1.88 (Nitinat) to 2252.23 (Chilliwack), and were additionally composed of differences in the contributions of each 226 independent behavioural trait (Figure 2C).

\section{Integrated effects of cortisol and behaviour on growth}

229 Daytime cortisol exposure had a negative linear relationship with behavioural phenotype $\left(R^{2}=\right.$ $2300.64, p=0.031$; Figure 3$)$, while nighttime cortisol exposure showed no such relationship $\left(R^{2}=\right.$ $2310.12, p=0.44)$. As univariate predictors of performance, nighttime cortisol exposure and 232 behavioural phenotype each showed a non-linear, hormetic relationship with body mass (cortisol: $233 R^{2}=0.94, p=0.003, \mathrm{AICc}=6.1$; quadratic regression: body mass $=\left(4.44-0.002 *\left(\mathrm{AUC}_{\mathrm{night}}-\right.\right.$ $23475.31)^{\wedge} 2$ ); (behaviour: $R^{2}=0.95, p=0.003$, AICc $=5.8$, quadratic regression: body mass $=$ $235\left(4.03-\left(0.12 *\right.\right.$ behaviour $\left.\left.^{\wedge} 2\right)\right) . \mathrm{AUC}_{\text {day }}$ had no effect on body mass (linear or quadratic 236 relationships; $R^{2}<0.4$, p-values $>0.36$, AICc's $>11.0$ ). However, the inclusion of both 237 nighttime cortisol exposure and behaviour increased the model's predictive ability and its 238 weighting to explain variation in body mass, with stocks exhibiting mid-range in nighttime 239 cortisol exposure and high energy-management behaviours having the largest body masses $\left(R^{2}=\right.$ $240 \quad 0.998, p=0.07, \mathrm{AICc}=-143.3$; Figure 4A). There was no meaningful or significant integration 
241 of daytime cortisol exposure with behavioural phenotype on body mass. All models tested are 242 included in Table S3.

\section{Discussion}

245 Rapid human population growth and increases in anthropogenic stressors on wild ecosystems 246 require improved efficiency in alternative food-production systems such as aquaculture to keep 247 pace with world demand for protein (Green et al. 2005). However, aquaculture practices such as 248 selecting for fast growing individuals can inadvertently decrease stock genetic diversity and/or 249 co-select for undesirable traits that will ultimately impact production (Castanheira et al. 2017).

250 We sought to determine whether outbreeding a domesticated Chinook salmon stock with 251 multiple wild populations resulted in the optimal integration of physiological and behavioural

252 traits at the nexus of energetic management, and if this integration lead to maximized 253 performance at an early-life freshwater stage. Outbreeding generated significant variability in

254 physiological and behavioural traits that are associated with energetic management and known to 255 impact growth. As predicted by the theory of phenotypic integration (Murren 2012), growth was 256 influenced by a coupling of nighttime cortisol exposure and behavioural phenotype, specifically

257 with intermediate cortisol values and high energy-management behaviours combining to 258 generate an optimized hormetic relationship to maximize body size. Our results also suggest that 259 examining the effects of the co-variation of multiple functionally related traits on body mass is a

260 stronger approach than examining these traits in isolation. Moreover, relationships that exist

261 between phenotypic traits such as daytime cortisol exposure and behaviour do not imply

262 integration (and by extension maximized performance), highlighting that only within the context 263 of a performance measure can phenotypic integration be revealed. While phenotypic correlations 
264 among traits have been extensively studied, fewer have been examined in light of performance-

265 or fitness outcomes, and fewer still across multiple populations. This is the first study to show

266 how among-population coupling of physiological and behavioural traits can influence early-life

267 metrics such as growth rate (here measured as body mass), considered important in assessing

268 long-term success in aquaculture (Valente et al. 2013). This work therefore suggests that

269 researchers and producers may benefit from determining how phenotypic integration impacts

270 early-life performance when employing methods such as outbreeding to enhance or rescue

271 breeding programs.

272

273 Impacts of outcrossing on variability in performance-mediated traits

274 Optimal management of energy budgets over both short- and long-term periods within the 275 constraints of local environmental variation is expected to maximize fitness (Fong 1975; Taylor

276 1991; Sanford \& Kelly 2011), a critical consideration for production output in aquaculture

277 (Akvaforsk 2005). Outbreeding in our study produced substantial variation in diel physiological

278 and behavioural traits central to daily energetic management. We focused on diel variation in

279 baseline cortisol because it can differentially affect growth by regulating metabolic processes and

280 promoting homeostasis in fish (Mommsen et al. 1999). In diurnal vertebrates, an optimal diel

281 cortisol cycle consists of high levels early in the morning to provide the energy via

282 gluconeogenesis following night fasting (Dallman et al. 1993), to initiate foraging and other

283 activities (Astheimer et al. 1992; Breuner et al. 1999; Breuner and Hahn 2003). Levels then tend

284 to decline for the remainder of the day to avoid the "high cost of living" associated with

285 maintaining high baseline circulating glucocorticoid levels (Sapolsky et al. 2000; Bernier et al.

286 2004). Although our data confirm that all populations showed strong diel rhythms in baseline 
287 cortisol, populations nonetheless differed significantly in patterns of cortisol exposure during

288 night and day. Outbreeding also generated a range in behavioural traits associated with energetic

289 management, and when combined with differences in cortisol exposure, revealed certain stocks

290 to be less ideally suited to captive environments as evidenced by the resultant low body size.

291 The differences observed among stocks are presumably driven by large sire effects that

292 result from genetic differences among the source stocks that have arisen through local adaptation

293 and potentially genetic drift (Fraser et al. 2011). The sire effect would have dominated possible

294 dam effects among stocks given that we used a common inbred line of domestic dams to both

295 minimize maternal effects and equalize any influences across all stocks (as eggs were also

296 pooled). Within our study, not all hybrid stocks showed high performance. While there are many

297 possible causes of this pattern of reduced performance, one may be the poor performance of the

298 F1 generation is due to the intermediate phenotypes generated by hybridization which are

299 unsuited to the domestic parental environments (Frankham et al. 2002; McClelland \& Naish

300 2007). Another mechanistic cause of lowered performance in hybrid stocks may be intrinsic

301 outbreeding depression due to the disruption of epistatic interactions in large co-adapted gene

302 complexes (Edmands 1999); however, we do not believe this to be the case since previous

303 studies have shown Chinook salmon F1 hybrids of genetically different parental lines

304 demonstrate no evidence of hybrid breakdown (Lehnert et al. 2014). Instead, suboptimal

305 performance of juvenile Chinook salmon of certain stocks most likely reflects local adaptation of

306 performance traits within freshwater systems that are very important for the success of early life-

307 history stages of anadromous, semelparous salmonids (Waples 1991). When different genotypes

308 are raised in common environments, the impacts of these locally adapted phenotypes persist and

309 are known to generate significant variation in performance outcomes (McClelland \& Naish 
310 2007), and so deliberate selection of these tightly integrated traits will be robust past the F1

311 generation and persist through multiple generations. However, the potential for non-additive

312 genetic effects coupled with residual epigenetic effects may interfere with the predictable

313 inheritance of some of the traits measured.

\section{Effects of outcrossing on the outcome of phenotypic integration under novel captive}

316 conditions

317 Traditionally, researchers have focussed on single traits rather than multi-trait combinations to

318 predict fitness or performance of wild populations (Gilmour et al. 2005; Killen et al. 2013).

319 However, since traits that depend on common mechanisms for their expression may evolve as a

320 unit (McGlothlin \& Ketterson 2008), ignoring the potential for synergistic effects of integrated

321 phenotypes on performance can limit our appreciation of their adaptive value (Pigliucci 2003;

322 Ketterson et al. 2009; Laughlin \& Messier 2015). In our study, examining interactions between

323 physiology and behaviour suggested that daytime cortisol exposure predicted behavioural

324 phenotype in a simple linear fashion, setting up the expectation that both would interact to

325 impact growth. However, an integrated phenotypic approach revealed it was the combination of

326 exposure to nighttime cortisol and behaviour that was the best predictor of maximized growth

327 across the 7 stocks, with stocks having mid-range nighttime cortisol exposure and maximal

328 energetics behaviour exhibiting the highest body mass (Figure 4A).

329 Chronically high cortisol levels are known to negatively impact behavioural traits such as

330 foraging and competitive ability due to a reduction in appetite (Gregory \& Wood 1999) and can

331 inhibit aggression and locomotion in salmonids (Øverli et al. 2002). As such, prolonged exposure

332 can lead to tertiary responses such as slow growth, reduced immune function, and compromised 
333 survival (Pickering \& Pottinger 1983; Barton 2002). In our study, stocks with individuals that

334 expressed elevated daytime cortisol exposure may have incurred these behavioural costs that led

335 to reduced growth. During nighttime, when fish were not fed and feeding activity was much

336 reduced (Fraser \& Metcalfe 1997), cortisol plays a more direct role in growth: elevated baseline

337 levels maintain energetic homeostasis, allowing stored glycogen in the liver (generated from

338 food consumed and digested during the day) to be mobilized as glucose to fuel the maintenance

339 and growth of tissues (see Dallman et al. 1993). Behaviours that promote energy gain while

340 reducing energetic costs of locomotion (including sociality) are generally assumed to lead to the

341 highest growth (e.g., foraging efficiency: Eklöv, 1992; high cohesiveness: Johnsson 2003).

342 Interestingly, as a sole (univariate) measure, these maximized behaviours seemingly had a

343 counter-intuitive, negative effect on growth (i.e., significant hormetic relationship), and yet as an

344 integrated unit with physiology, these same behaviours conferred the greatest performance. We

345 therefore argue that an integrated approach situated within a performance context is needed to

346 understand how underlying traits will ultimately impact performance in aquaculture. We also

347 demonstrate that with this integrated relationship - visualized as a contour plot (Figure 4B), there

348 exists the potential for further selection of integrated traits to maximize production. For instance,

349 actively selecting for specific behaviours (i.e., greater locomotory-, foraging efficiency, and

350 sociality) - should these traits remain co-varied within a physiological range, can result in even

351 greater mass gains than those observed. This integrated selection approach at the stock level can

352 be of value for other performance traits (such as disease resistance) and in other breeding

353 programs, outside of salmon culture: it is not only feasible for farming methods that must

354 routinely document production data of functional traits and performance on a large scale, but can

355 be used to possibly increase efficiency as well. 


\section{Conclusions}

357 While phenotypic integration can increase organismal performance by optimizing the adaptive

358 phenotype over evolutionary time, it may decrease flexibility in a changing environment

359 (Schlichting 1989). This apparent trade-off is an important realization for evolutionary biologists

360 and applied producers since both robust and flexible phenotypes carry costs due to (1) the

361 potential for a "mismatched" phenotype to a given environment (Hendry 2004; Nosil et al. 2005)

362 and (2) the associated energetic costs of flexibility (DeWitt et al. 1998; Snell-Rood 2013),

363 respectively. In fact, with regards to food production, abrupt changes in environment (e.g., from

364 the wild to captivity, or fresh water to salt water) may better suit a less flexible and instead a

365 more integrated phenotype, as the temporal lag in endocrine activity and its associated

366 behavioural response may be too slow (and take several generations) to adaptively respond to

367 changing conditions (Taff \& Vitousek 2016). Since the management of cortisol is intimately

368 involved in the osmoregulatory transition of fish from fresh to salt water (rev. in McCormick

369 2012), we would predict that (above and beyond energetic management) a tighter integration

370 between cortisol and behaviour could also result in a less costly transition. Taken together,

371 appreciating population-level effects associated with integrated energetic management has the

372 ability to better inform researchers and aquaculture producers about early-life stage mechanisms

373 that influence variation in growth and survival (Valente et al. 2013), and that can also undergo

374 intentional selection for increased food production long-term. 


\section{Acknowledgements}

378 We thank Yellow Island Aquaculture Ltd, especially Dr. Ann Heath, J. Drown and the YIAL

379 staff (N. Antoniolli, K. Jones, E. Haugen and D. Meester) for fish care and providing the

380 facilities for the experiments. We also thank C. Harris and K. Janisse for lab assistance, and all

381 field volunteers. This manuscript was improved by the input of three anonymous reviewers. We

382 thank the Natural Sciences and Engineering Research Council (NSERC) of Canada for Strategic

383 Partnership Grant and Discovery Grant funding to DDH, OPL, and CADS, and the Canada

384 Research Chairs program for funding to OPL. All research followed the University of Windsor

385 Animal Care Committee guidelines (AUPP \#13-22) for the care and use of animals and complied

386 with the Canadian Council on Animal Care guidelines. 
387

388 389

\section{References}

Akvaforsk $\AA .2005$ Selection and breeding programs in aquaculture. Gjedrem T, editor. Dordrecht: Springer.

Allendorf FW, Leary RF, Spruell P, Wenburg JK. 2001 The problems with hybrids: setting conservation guidelines. Trends Ecol. Evol. 16, 613-622. (doi:10.1016/S01695347(01)02290-X)

Almazán-Rueda P, Van Helmond ATM, Verreth JAJ, Schrama JW. 2005 Photoperiod affects growth, behaviour and stress variables in Clarias gariepinus. J. Fish Biol. 67, 10291039. (doi:10.1111/j.0022-1112.2005.00806.x)

Arkush KD, Giese AR, Mendonca HL, McBride AM, Marty GD, Hedrick PW. 2002 Resistance to three pathogens in the endangered winter-run chinook salmon (Oncorhynchus tshawytscha): effects of inbreeding and major histocompatibility complex genotypes. Can. J. Fish Aquat. Sci. 59, 966-975. (doi:10.1139/f02-066)

Astheimer LB, Buttemer WA, Wingfield JC. 1992 Interactions of corticosterone with feeding, activity and metabolism in passerine birds. Ornis Scand. 23, 355-365. (doi:10.2307/3676661)

Barton BA. 2002 Stress in fishes: a diversity of responses with particular reference to changes in circulating corticosteroids. Integr. Comp. Biol. 42, 517-525. (doi:10.1093/icb/42.3.517)

Bennett MG, Whiles MR, Whitledge GW. 2016 Population $\square$ level responses of life history traits to flow regime in three common stream fish species. Ecohydrology 9,1388-1399.

Bentsen HB, Olesen I. 2002 Designing aquaculture mass selection programs to avoid high inbreeding rates. Aquaculture 204, 349-359. (doi:10.1016/S0044-8486(01)00846-8) 
409

410

Bernier NJ, Bedard N, Peter RE. 2004 Effects of cortisol on food intake, growth, and forebrain neuropeptide Y and corticotropin-releasing factor gene expression in goldfish. Gen. Comp. Endocrinol. 135, 230-240. (doi:10.1016/j.ygcen.2003.09.016)

Boisclair D, Sirois P. 1993 Testing assumptions of fish bioenergetics models by direct estimation of growth, consumption, and activity rates. T. Am. Fish Soc. 122, 784-796. (doi:10.1577/1548-8659)

Bremset, G. 2000 Seasonal and diel changes in behaviour, microhabitat use and preferences by young pool-dwelling Atlantic salmon, Salmo salar, and brown trout, Salmo trutta. Env. Biol. Fishes. 59, 163-179. (doi:10.1023/A:100769131)

Breuner CW, Hahn TP. 2003 Integrating stress physiology, environmental change, and behavior in free-living sparrows. Horm. Behav. 43, 115-123. (doi:10.1016/S0018-506X(02)00020X)

Breuner CW, Wingfield JC, Romero LM. 1999 Diel rhythms of basal and stress-induced corticosterone in a wild, seasonal vertebrate, Gambel's white-crowned sparrow. J. Exp. Zool. 284, 334-342. (doi:10.1002/(SICI)1097-010X(19990801)284:3<334::AID$\mathrm{JEZ11>3.0.CO;2- \# )}$

Capelle PM, Semeniuk CAD, Sopinka NM, Heath JW, Love OP. 2016 Prenatal stress exposure generates higher early survival and smaller size without impacting developmental rate in a Pacific salmon. J. Exp. Zool. Part A 325, 641-650. (doi:10.1002/jez.2058)

Carlson SM, Seamons TR. 2008 A review of quantitative genetic components of fitness in salmonids: implications for adaptation to future change. Evol. Appl. 1, 222-238. (doi:10.1111/j.1752-4571.2008.00025.x) 
431 Castanheira MF, Herrera M, Costas B, Conceição LE, Martins CIM. 2013 Can we predict personality in fish? Searching for consistency over time and across contexts. PLoS One.

434 Castanheira MF, Conceicao LEC, Millot S, Rey S, Bégout M-L, Damsgard B, Kristiansen T, Höglund E, Øverli Ø, Martins CIM 2017 Coping styles in farmed fish: consequences for aquaculture." Reviews in Aquaculture 9: 23-41.

Clapp J, Cohen MJ, editors. 2009 The global food crisis: Governance challenges and opportunities. Wilfrid Laurier Univ. Press. 1, 1-288.

Dallman MF, Strack AM, Akana SF, Bradbury MJ, Hanson ES, Scribner KA, Smith M. 1993 Feast and famine: critical role of glucocorticoids with insulin in daily energy flow. Front.

DeWitt TJ, Sih A, Wilson DS. 1998 Costs and limits of phenotypic plasticity. Trends Ecol. Evol. Neuroendocrinol. 14, 303-347. (doi:10.1006/frne.1993.1010)

444 Edmands S. 1999 Heterosis and outbreeding depression in interpopulation crosses spanning a wide range of divergence. Evolution 53, 1757-1768. (doi:10.2307/2640438) 13, 77-81. (doi:10.1016/S0169-5347(97)01274-3)

Edmands S. 2007 Between a rock and a hard place: evaluating the relative risks of inbreeding and outbreeding for conservation and management. Mol. Ecol. 16, 463-475. (doi:10.1111/j.1365-294X.2006.03148)

Eklöv P. 1992 Group foraging versus solitary foraging efficiency in piscivorous predators: the perch, Perca fluviatilis, and pike, Esox lucius, patterns. Anim. Behav. 44, 313-326. (doi:10.1016/0003-3472(92)90037-A)

FAO. 2016 The State of World Fisheries and Aquaculture. Rome. 1-204. 
453 Fernö A, Furevik DM, Huse I, Bjordal Å. 1988 A multiple approach to behaviour studies of 454 salmon reared in marine net pens. ICES.

455 Fernö A, Huse I, Juell J-E, Bjordal Å. 1995 Vertical distribution of Atlantic salmon (Salmo salar

456 L.) in net pens: trade-off between surface light avoidance and food attraction. Aquaculture 132, 285-296. (doi:10.1016/0044-8486(94)00384-Z)

458 Frankham R, Briscoe DA, Ballou JD. 2002 Introduction to conservation genetics. Cambridge $459 \quad$ University Press.

460 Fraser NH, Metcalfe NB. 1997 The costs of becoming nocturnal: feeding efficiency in relation to 461 light intensity in juvenile Atlantic salmon. Funct. Ecol. 11, 385-391.

463 Fraser DJ, Weir LK, Bernatchez L, Hansen MM, Taylor EB. 2011 Extent and scale of local 464 adaptation in salmonid fishes: review and meta-analysis. Heredity 106, 404-420. (doi:10.1038/hdy.2010.167)

Fong H. 1975 Animal physiology: adaptation and environment. Yale J. Biol. Med. 48, 262-263.

467 Gharrett AJ, Smoker WW, Reisenbichler RR, Taylor SG. 1999 Outbreeding depression in 468 hybrids between odd-and even-broodyear pink salmon. Aquaculture 173, 117-129. (doi:10.1016/S0044-8486(98)00480-3)

470 Gilmour KM, Wilson RW, Sloman KA. 2005 The integration of behaviour into comparative physiology. Physiol. Biochem. Zool. 78, 669-678. (doi:10.1086/432144)

472 Green RE, Cornell SJ, Scharlemann JP, Balmford A. 2005 Farming and the fate of wild nature.

$473 \quad$ Science 307, 550-555. (doi:10.1126/science.1106049) 
474 Gregory TR, Wood CM. 1999 The effects of chronic plasma cortisol elevation on the feeding 475 behaviour, growth, competitive ability, and swimming performance of juvenile rainbow trout. Physiol. Biochem. Zool. 72, 286-295. (doi:10.1086/316673)

477 Gries, G, Whalen, KG, Juanes, F, Parrish, DL. 1997 Nocturnal activity of juvenile Atlantic 478 salmon (Salmo salar) in late summer: evidence of diel activity partitioning. Can. J. Fish. Aquat. Sci. 54, 1408-1413. (doi:10.1139/f97-046)

Heath DD, Fox CW, Heath JW. 1999 Maternal effects on offspring size: variation through early development of chinook salmon. Evolution 53, 1605-1611. (doi:10.2307/2640906)

Henchion M, Hayes M, Mullen AM, Fenelon M, Tiwari, B. 2017 Future protein supply and 483 demand: strategies and factors influencing a sustainable equilibrium. Foods, 6, 53. dependent reproductive isolation. Evol. Ecol. Res. 6, 1219-1236.

Johnsson JI. 2003 Group size influences foraging effort independent of predation risk: an Hendry AP. 2004 Selection against migrants contributes to the rapid evolution of ecologically experimental study on rainbow trout. J. Fish Biol. 63, 863-870. (doi:10.1046/j.10958649.2003.00187.x)

Ketterson ED, Atwell JW, McGlothlin JW. 2009 Phenotypic integration and independence: hormones, performance, and response to environmental change. Integr. Comp. Biol. 49, 365-379. (doi:10.1093/icb/icp057)

Killen SS, Marras S, Metcalfe NB, McKenzie DJ, Domenici P. 2013 Environmental stressors alter relationships between physiology and behaviour. Trends Ecol. Evol. 28, 651-658. (doi:10.1016/j.tree.2013.05.005)

Kincaid HL. 1983 Inbreeding in fish populations used for aquaculture. Aquaculture 33, 215-227. (doi:10.1016/0044-8486(83)90402-7) 
497 Lancaster LT, McAdam AG, Sinervo B. 2010 Maternal adjustment of egg size organizes

498 alternative escape behaviors, promoting adaptive phenotypic integration. Evolution 64, 1607-1621. (doi:10.1111/j.1558-5646.2009.00941)

500 Laughlin DC, Messier J. 2015 Fitness of multidimensional phenotypes in dynamic adaptive landscapes. Trends Ecol. Evol. 30, 487-496. (doi:10.1016/j.tree.2015.06.003)

502 Lehnert SJ, Love OP, Pitcher TE, Higgs DM, Heath DD. 2014 Multigenerational outbreeding effects in Chinook salmon (Oncorhynchus tshawytscha). Genetica 142, 281-293. (doi:10.1007/s10709-014-9774-5)

Martins CIM, Schrama JW, Verreth JAJ. 2006 The effect of group composition on the welfare of African catfish (Clarias gariepinus). Appl. Anim. Behav. Sci. 97, 323-334. (doi:10.1016/j.applanim.2005.07.003)

Mazerolle MJ, Mazerolle MM. 2017. Package 'AICcmodavg'.

McClelland EK, Naish KA. 2007 What is the fitness outcome of crossing unrelated fish populations? A meta-analysis and an evaluation of future research directions. Conserv. Genet. 8, 397-416. (doi:10.1007/s10592-006-9178-x)

512 McCormick, SD. 2012 Smolt physiology and endocrinology. Fish Physiol. 32, 199-251. (doi: $\underline{0.1016 / \mathrm{B} 978-0-12-396951-4.00005-0}$ )

514 McGlothlin JW, Jawor JM, Ketterson ED. 2007 Natural variation in a testosterone-mediated trade-off between mating effort and parental effort. Am. Nat. 170, 864-875. (doi:10.1086/522838) constraints. Philos. T. Roy. Soc. B 363, 1611-1620. (doi:10.1098/rstb.2007.0002) 
519 Mommsen TP, Vijayan MM, Moon TW. 1999 Cortisol in teleosts: dynamics, mechanisms

520 ofaction, and metabolic regulation. Rev. Fish Biol. Fisher. 9, 211-268. (doi:10.1023/A:1008924418720)

Murren CJ. 2012 The integrated phenotype. Integr. Comp. Biol. 52, 64-76. (doi:10.1093/icb/ics043)

524 Neff BD, Garner SR, Pitcher TE. 2011 Conservation and enhancement of wild fish populations: preserving genetic quality versus genetic diversity. Can. J. Fish Aquat. Sci. 68, 1139-

Nosil P, Vines TH, Funk DJ. 2005 Reproductive isolation caused by natural selection against 1154. (doi:10.1139/F2011-029) immigrants from divergent habitats. Evolution 59, 705-719. (doi:10.1554/04-428)

Øverli Ø, Kotzian S, Winberg S. 2002 Effects of cortisol on aggression and locomotor activity in rainbow trout. Horm. Behav. 42, 53-61. (doi:10.1006/hbeh.2002.1796)

533 Pavlidis 1999. The effect of photoperiod on diel rhythms in serum melatonin, cortisol, glucose, and electrolytes in the common dentex Dentex dentex. Gen. Comp. Endocrinol. 113, 240-

536 Pickering AD, Pottinger TG. 1983 Seasonal and diel changes in plasma cortisol levels of the brown trout, Salmo trutta L. Gen. Comp. Endocrinol. 49, 232-239. (doi:10.1016/00166480(83)90139-9)

Pigliucci M. 2003 Phenotypic integration: studying the ecology and evolution of complex phenotypes. Ecol. Lett. 6, 265-272. (doi:10.1046/j.1461-0248.2003.00428.x) 
541 Piper, RG, McElwain, IB, Orme, LE, McCraren, JP, Fowler, LG, Leonard, JR. 1982) Fish

542 hatchery management. United States Department of of the Interior Fish and Wildlife

$543 \quad$ Service, Washington, D.C., USA.

544 Pruessner JC, Kirschbaum C, Meinlschmid G, Hellhammer DH. 2003 Two formulas for computation of the area under the curve represent measures of total hormone concentration versus time-dependent change. Psychoneuroendocrino. 28, 916-931. (doi:10.1016/S0306-4530(02)00108-7)

Sanford E, Kelly MW. 2011 Local adaptation in marine invertebrates. Annu. Rev. Mar. Sci. 3, 509-535. (doi:10.1146/annurev-marine-120709-142756)

550 Sapolsky RM. 2000 Stress hormones: good and bad. Neurobiol. Dis. 7, 540-542. (doi:10.1006/nbdi.2000.0350)

552 Schlichting CD. 1989 Phenotypic integration and environmental changes. BioScience 39, 460464.

554 Schreck CB. Stress and fish reproduction: the roles of allostasis and hormesis. 2010 Gen. Comp. Endocrinol. 165, 549-556. (doi: 10.1016/j.ygcen.2009.07.004)

556 Semeniuk CAD, Capelle P, Dender M, Devlin R, Dixon B, Drown J, Heath J, Hepburn R, Higgs D, Janisse K, Lehnert S, Love O, Mayrand J, Mickle M, Pitcher T, Neff B, Semple S, 8486(99)00076-9) 
563 Snell-Rood EC. 2013 An overview of the evolutionary causes and consequences of behavioural plasticity. Anim. Behav. 85, 1004-1011. (doi:10.1016/j.anbehav.2012.12.031)

Su G-S, Liljedahl L-E, Gall GAE. 1996 Effects of inbreeding on growth and reproductive traits in rainbow trout (Oncorhynchus mykiss). Aquaculture 142, 139-148. (doi:10.1016/00448486(96)01255-0) Trends Ecol. Evol. 31, 476-488. (doi:10.1016/j.tree.2016.03.005)

Tallmon DA, Luikart G, Waples RS. 2004 The alluring simplicity and complex reality of genetic

Taff CC, Vitousek MN. 2016 Endocrine flexibility: optimizing phenotypes in a dynamic world? rescue. Trends Ecol. Evol. 19, 489-496. (doi:10.1016/j.tree.2004.07.003)

Taylor EB. 1991 A review of local adaptation in Salmonidac, with particular reference to Pacific and Atlantic salmon. Aquaculture 98, 185-207. (doi:10.1016/0044-8486(91)90383-I)

Thorpe, JE, McConway, MG, Miles, MS, Muir, JS. 1987 Diel and seasonal changes in resting plasma cortisol levels in juvenile Atlantic salmon, Salmo salar L. Gen. Comp. Endocrinol. 65, 19-22. (doi:10.1016/0016-6480(87)90217-6)

Tymchuk WE, Biagi C, Withler R, Devlin RH. 2006 Growth and behavioral consequences of

Valente, LMP, Moutou, KA, Conceição, LEC, Engrola, S, Fernandes, JMA, Johnston, IA. 2013. What determines growth potential and juvenile quality of farmed fish species? Rev. Aquacul. 5, S168-S193. (doi:10.1111/raq.12020)

Waples RS. 1991 Pacific salmon, Oncorhynchus spp., and the definition of "species" under the Endangered Species Act. Mar. Fish. Rev. 53, 11-22. 
586 Whitlock MC, Ingvarsson PK, Hatfield T. 2000 Local drift load and the heterosis of 587 interconnected populations. Heredity 84, 452-457. (doi:10.1046/j.13652540.2000.00693.x) 
590 Figure 1. Map of British Columbia, Canada showing the source of wild Chinook salmon stocks

591 used for outbreeding in the study. A captive, inbred stock was used as the basis for all crosses

592 and is held at Yellow Island Aquaculture Ltd. Colours: Bright green - YIAL; purple - Robertson

593 Creek; orange - Quinsam River; pink - Puntledge River; light blue -Nitinat River; dark blue -

594 Chilliwack River; dark green - Capilano River; red -Big Qualicum River.

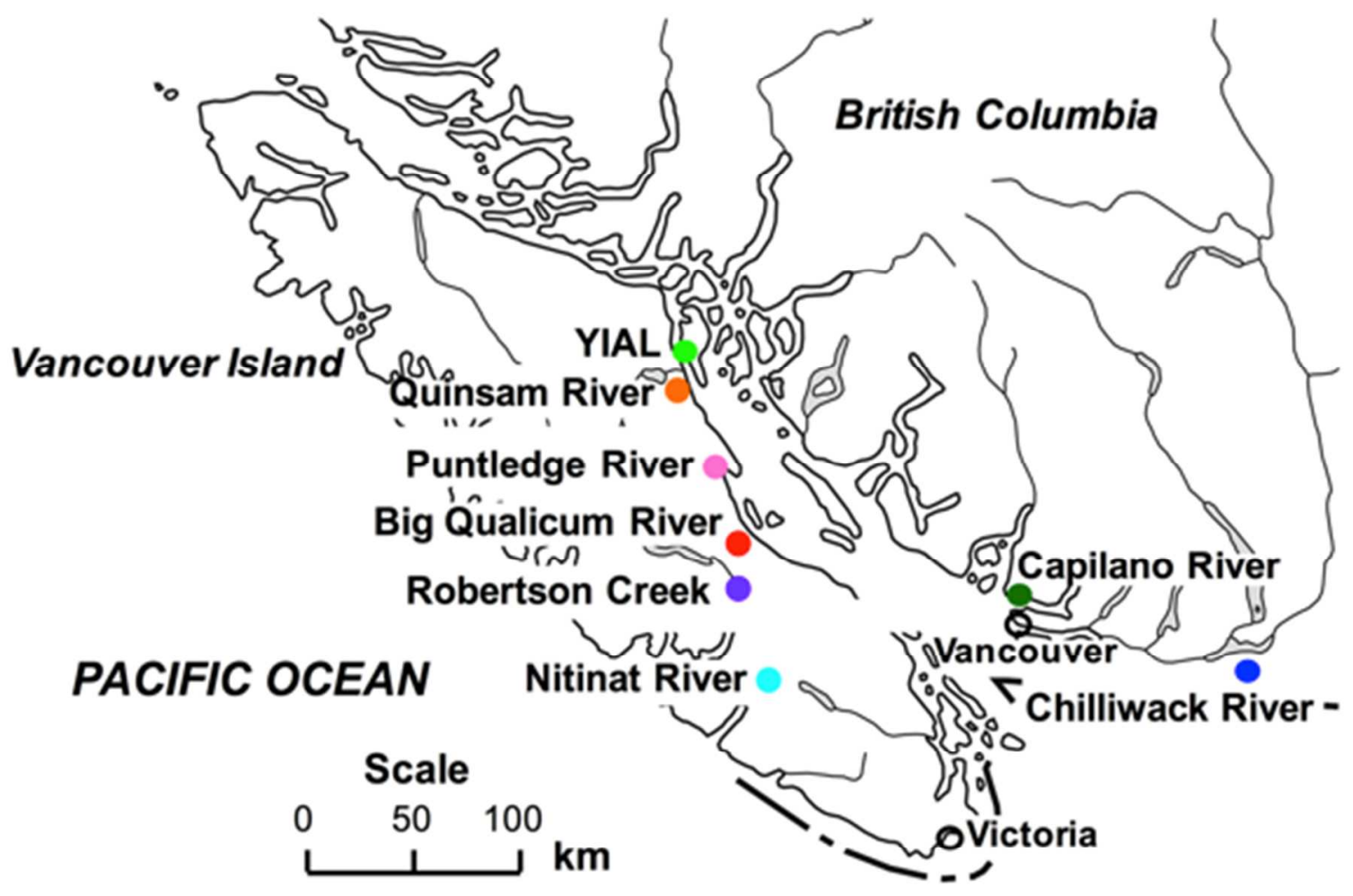


Figure 2. Inter-population variation in (A) diel patterns of baseline cortisol secretion, (B)

597 daytime and nighttime exposure to baseline cortisol, and (C) variation in behavioural traits of

598 Chinook salmon parr.
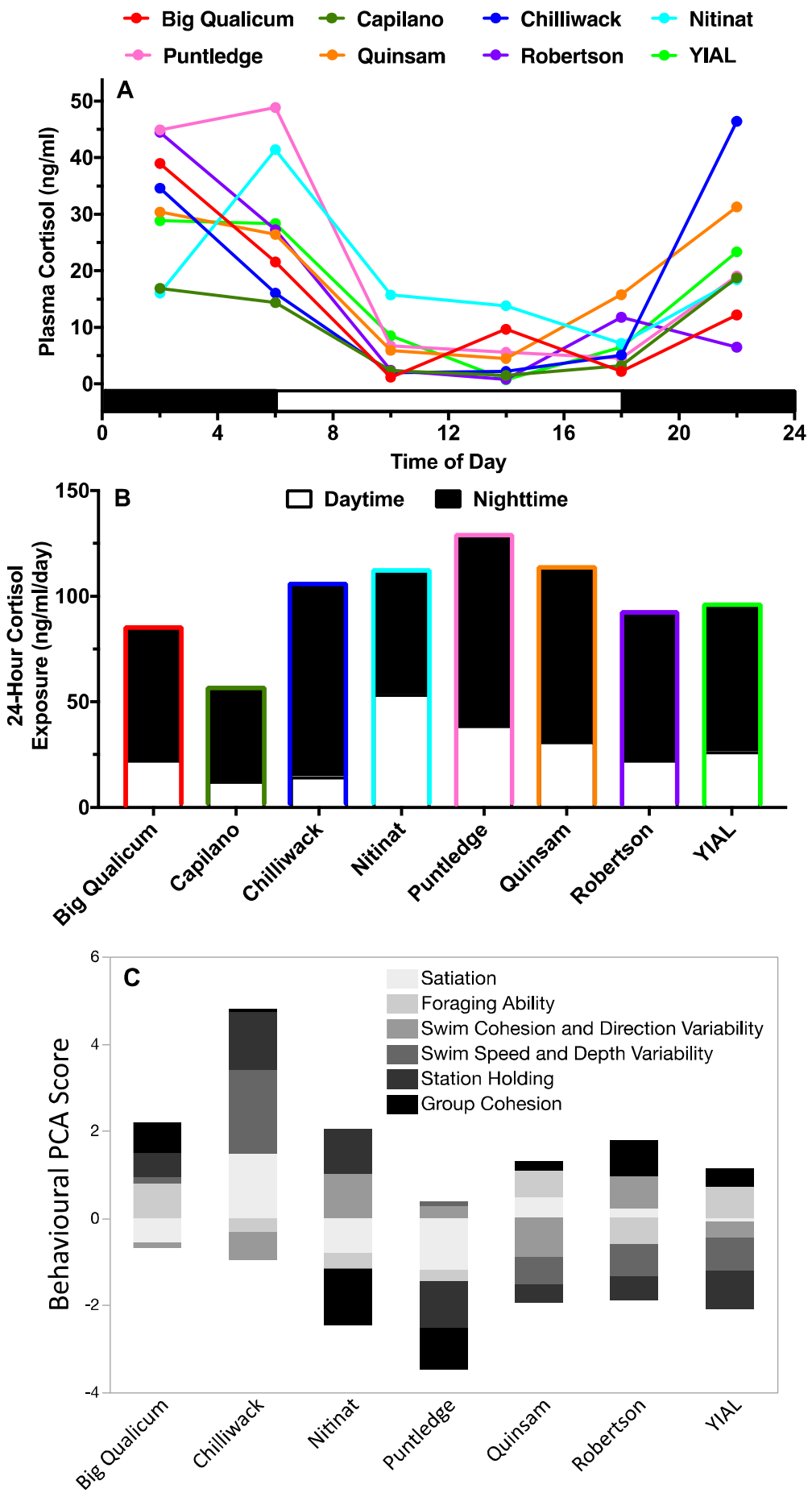
Figure 3. Exposure to daytime cortisol predicts overall behavioural phenotype (combination of foraging, sociality, and movement behaviours) as a linear relationship across 6 outbred populations of Chinook salmon and the inbred control population.

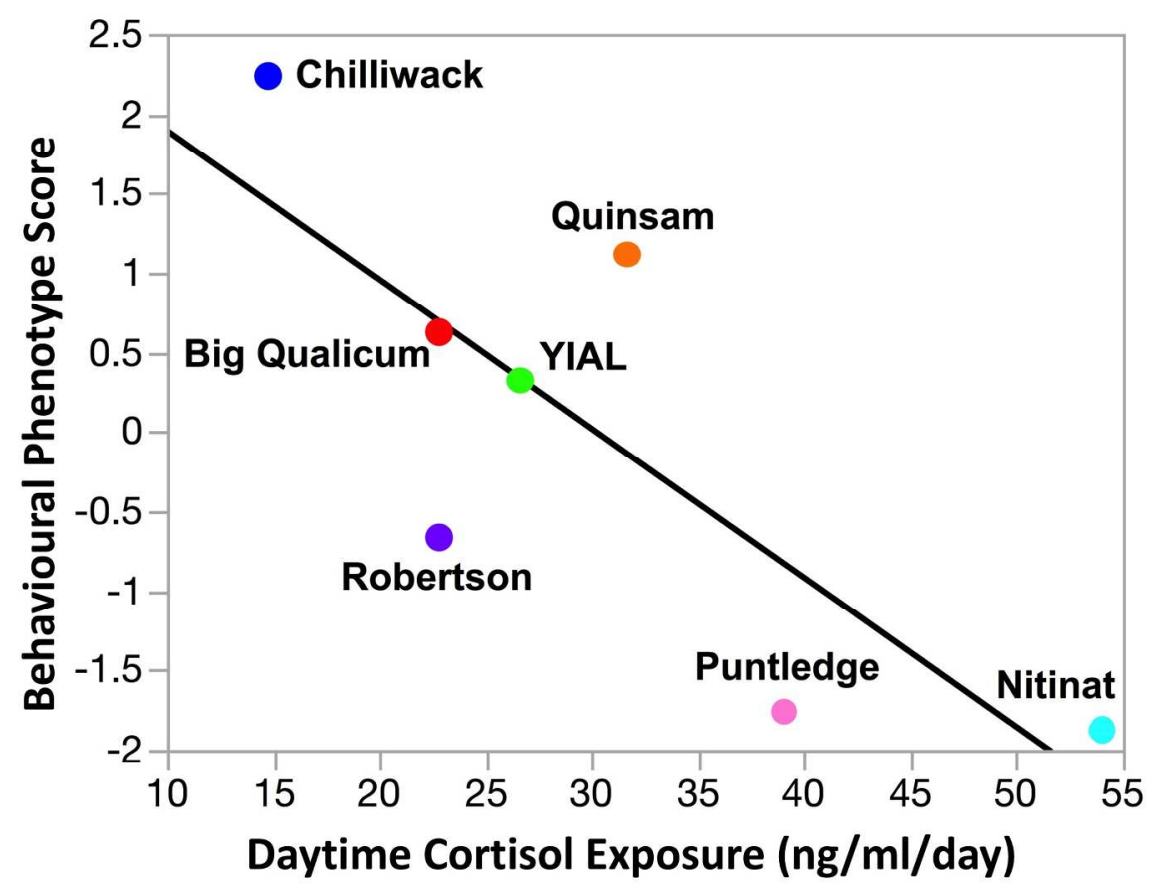


Figure 4. Body mass outcome of optimal phenotypic integration between exposure to cortisol during the night and overall behavioural phenotype (see Methods) across 6 outbred populations of Chinook salmon and the inbred control population (YIAL), represented as both (A) a threedimensional plot and (B) as a contour map.

A

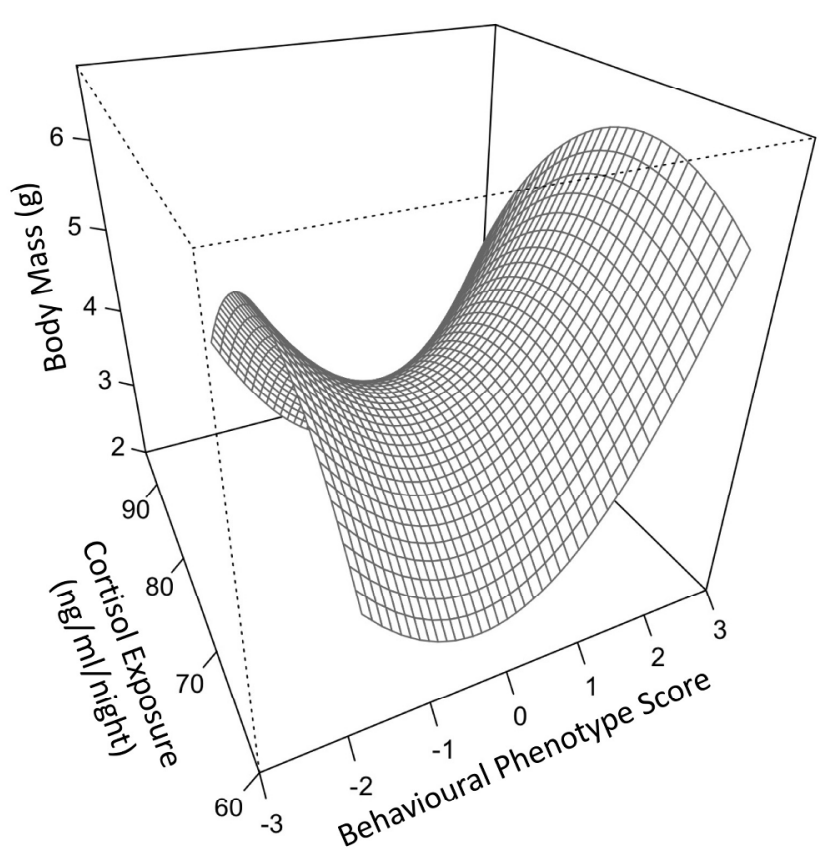

B

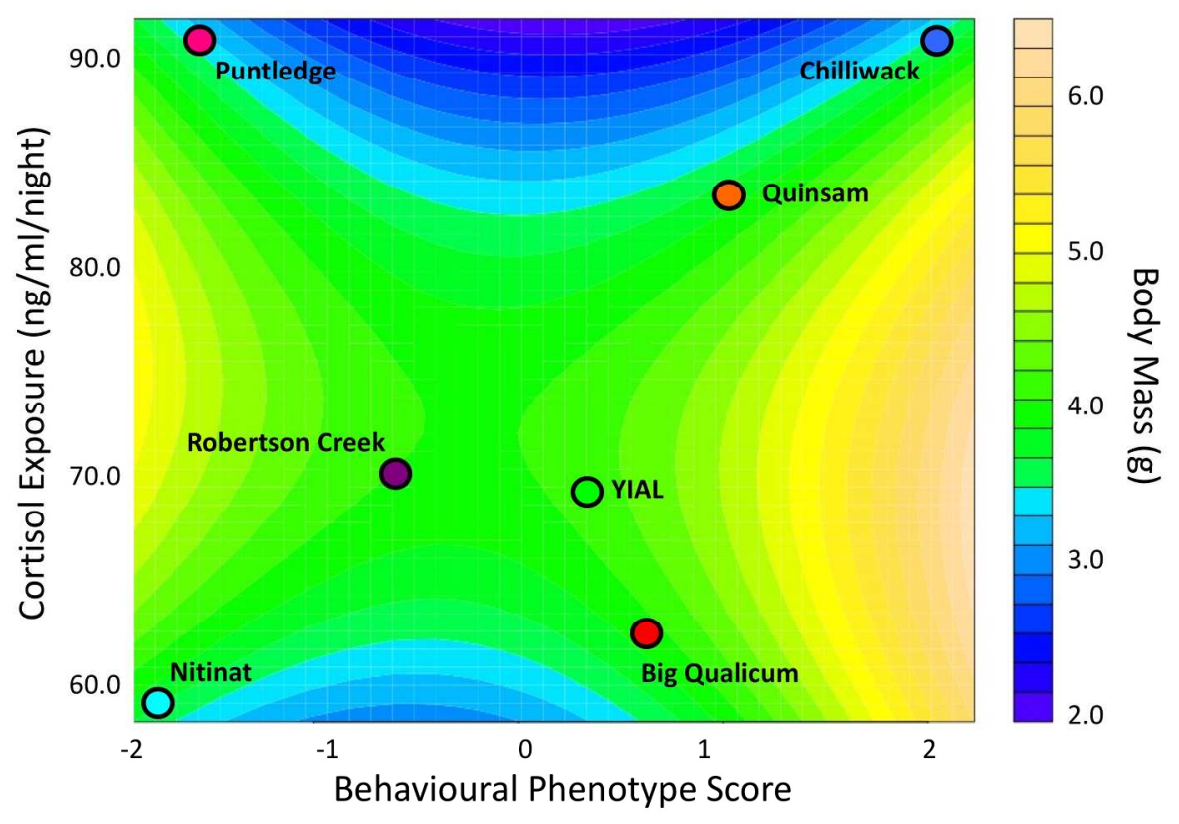

